\title{
Los 30 años de la Convención de los Derechos del Niño: una mirada crítica sobre su vigencia ${ }^{1}$
}

\author{
Lucía Belaunzarán, Martina Flaherty, Martín Menestrina, \\ Sebastián P. Pagano y Lucía F. Zapico Feltri \\ Universidad Nacional de La Plata - Argentina
}

Revista Derechos en Acción ISSN 2525-1678/ e-ISSN 2525-1686 Año 5/NN 14, Verano 2019-2020 (21 diciembre a 20 marzo), 831-840 DOI: https://doi.org/10.24215/25251678e377

\section{La Convención sobre los Derechos del Niño}

La Convención sobre los Derechos del Niño (en adelante $\mathrm{CDN}$ ) es un tratado internacional de derechos humanos, aprobado el 20 de noviembre de 1989 por la Asamblea General de las Naciones Unidas luego de un debate que duró más de 20 años. Es el instrumento internacional más importante sobre los derechos de niñas, niños y adolescentes, y en términos generales, el que ha tenido mayor aceptación y consenso. En efecto, la CDN se convirtió el 20 de septiembre de 1990 en el tratado que más rápido entró en vigencia en la historia del derecho internacional, así como también fue la convención ratificada por más países del mundo, todos a excepción de Estados Unidos.

Antes de la Convención de los Derechos del Niño, existieron dos declaraciones de la comunidad internacional. La primera fue

\footnotetext{
Programa de Niñez, Derechos Humanos y Políticas Públicas perteneciente a la Secretaría de Extensión de la Facultad de Cs. Jurídicas y Sociales de la UNLP. El Programa está coordinado por el Abog. Martin Menestrina, y los miembros del equipo son: Ia Lic. en Trabajo Social Lucía Belauzarán, el Lic. en Psicología Manuel Rodriguez, la Abog. Antonela Coroli y la Abog. Martina E. Flaherty. S.
} 
adoptada por la Sociedad de las Naciones en 1924 y la segunda por la Organización de Naciones Unidas en 1959. Si bien ambas declaraciones fueron un destacado avance en la materia y configuraron importantes antecedentes para la Convención de los Derechos del Niño, no eran más que enunciaciones de derechos y principios -sin un ser jurídicamente vinculantes- para orientar a los estados, en un mundo de posguerra, acerca de cómo se debía tratar a los niños y a las niñas.

La CDN cuenta con una primera parte donde se reconocen los derechos de los niños, niñas y adolescentes y una segunda parte donde se crea el Comité de los Derechos del Niño (en adelante el Comité) con la finalidad de examinar los progresos realizados en el cumplimiento de las obligaciones contraídas por los Estados.

En esa primera parte el eje fundamental de la CDN es el reconocimiento de los niños, niñas y jóvenes como sujetos de derechos que, junto con el establecimiento de su derecho a ser escuchados, el derecho a vivir una vida sin discriminación y el derecho a la sobrevivencia y el desarrollo, constituyó un cambio de paradigma respecto del viejo modelo del patronato.

Aquél antiguo sistema respondía a "un esquema que boy conocemos como 'modelo tutelar', 'filantrópico', 'de la situación irregular', o 'asistencialista', que tenía como punto de partida la consideración del menor como objeto de protección, circunstancia que legitimaba prácticas peno-custodiales y represivas encubiertas" (Beloff, 2004).

En el patronato, la utilización de estigmas tales como "riesgo", "abandono", "fuga del hogar", "niños de la calle y en la calle", entre otros, permitían tipificar una clase de personas que se encontraban "en situación irregular", conformando una identidad social que los aislaba de su entorno. Se pretendía salvar al niño considerándolo peligroso. De ese modo, en lugar de adoptar políticas públicas preventivas de protección integral de la familia y sus hijos, que mejoraran la calidad de sus vidas y las fortalecieran en su función de crianza y educación, se 
acudía a la "justicia de menores", mediante el alejamiento del niño del binomio familia-escuela, que sólo lograban marginarlo y excluirlo de su vida social.

De allí que se haya dicho que "La utilización del aparato de la administración de justicia en forma sistemática para este estrato poblacional ha estado desde siempre directamente vinculada a la ausencia de políticas públicas de promoción y desarrollo" (Guemureman y Daroqui, 2001).

Desde el lado opuesto, la doctrina de la "protección integral" implica la consideración de los niños, niñas y adolescentes como sujetos de derechos, es decir, como titulares de todos los derechos contemplados en los instrumentos internacionales y, a la vez, tienen derechos específicos previstos, precisamente, por su condición de personas en etapa de crecimiento.

Este nuevo paradigma implicó no sólo la introducción de garantías a la respuesta estatal al delito de los jóvenes, sino a la posibilidad de discutir la formulación de políticas públicas desde una perspectiva de derechos humanos, teniendo como eje al niño como sujeto de derechos. En efecto, se circunscribe la labor del juez a la resolución de conflictos de naturaleza jurídica, fortalece las garantías procesales y obliga a la Administración pública a implementar políticas integrales que remuevan los obstáculos que limitan la igualdad y la libertad, impidan o entorpezcan el pleno desarrollo de los niños y su efectiva participación en la comunidad; todo lo cual constituye una condición para el ejercicio pleno de los derechos reconocidos por la CDN.

La segunda parte de la CDN crea un Comité Internacional para examinar los progresos en el cumplimiento de las obligaciones contraídas por los Estados, que actualmente tiene sede en Ginebra. También la CDN obliga a los Estados que la ratificaron, a presentar informes periódicos sobre las medidas que se han adoptado para hacer efectivos los derechos de los niños, niñas y adolescentes. 


\section{Incorporación de la CDN al sistema jurídico argentino y bonaerense}

La CDN se incorporó al ordenamiento jurídico argentino, a partir de 1990 cuando dicha Convención fue ratificada (ley 23.849), y en el año 1994 se le otorgó jerarquía constitucional (art. 75 inc. 22 de la CN).

Al firmar la CDN los Estados asumen las obligaciones y los deberes, en virtud del derecho internacional, de respetar, proteger y realizar los derechos en ella incluidos. La obligación de respetarlos significa que los Estados deben abstenerse de interferir en el disfrute de los derechos humanos, o de limitarlos. La obligación de protegerlos exige que los Estados impidan los abusos de los derechos humanos contra individuos y grupos. La obligación de realizarlos significa que los Estados deben adoptar medidas positivas para facilitar el disfrute de los derechos humanos básicos.

A través de la ratificación de los tratados internacionales de derechos humanos, los gobiernos se comprometen a adoptar medidas y leyes internas compatibles con las obligaciones y deberes dimanantes de los tratados.

Sin embargo, frente al incumplimiento de adecuar la normativa interna para hacer efectivos los derechos reconocidos en la CDN, en el año 2002 el Comité de los Derechos del Niño expresó su preocupación respecto que "la ley vigente relativa al niño, a saber, la Ley $N^{\circ} 10.903$ (Ley de patronato), se remonte a $1919 y$ se base en la doctrina de la "situación irregular", en virtud de la cual los niños son objeto de protección judicial... de manera que no existe ninguna ley nacional vigente en que se considere que el niño es sujeto de derechos. Además, el Comité observa que, con frecuencia, la legislación provincial no se ajusta a las disposiciones y los principios de la Convención" (Naciones Unidas, Comité de los Derechos del Niño, 2002) y recomendó al Estado Nacional "a) Tome todas las medidas necesarias para que el Congreso apruebe sin tardanza el proyecto de ley de protección integral de los derechos del niño y el adolescente; b) Vele 
por que, una vez promulgada, la Ley de protección integral de los derechos del niño y el adolescente se aplique plenamente de conformidad con la Convención, prestando especial atención a la necesidad de asignar los recursos bumanos y financieros necesarios para poder contar con estructuras adecuadas".

Recién en el año 2005 -más de 11 años después de la ratificación de la CDN- fue sancionada la ley nacional 26.061 que creó el Sistema de Protección Integral de Derechos de Niños, Niñas y Adolescentes, en ese mismo año la Provincia de Buenos Aires sancionó la ley 13.298 de "Promoción y Protección Integral de los Derechos de los Niños", que asimismo derogó el decreto-ley 10.067/83 "Ley de patronato provincial".

\section{EI Sistema de Promoción y Protección Integral de los Derechos de los Niños}

La ley 13.298 pretendió crear en el territorio de la Provincia de Buenos Aires el Sistema de Promoción y Protección Integral de los Derechos del Niño (en adelante SPPDN) que debía estar conformado por un conjunto de organismos, entidades y servicios que formulan, coordinan, orientan, supervisan, ejecutan y controlan las políticas, programas y acciones, en el ámbito provincial y municipal, destinados a promover, prevenir, asistir, proteger, resguardar y restablecer los derechos de los niños, así como establecer los medios a través de los cuales se asegure el efectivo goce de los derechos y garantías reconocidos en la Constitución Nacional, la Constitución de la Provincia de Buenos Aires, la Convención sobre los Derechos del Niño, y demás tratados de Derechos Humanos ratificados por el Estado Argentino.

Entre los principales organismos administrativos que debían ponerse en funcionamiento -en remplazo del Patronato de Menores- se pueden mencionar: a) la Autoridad de Aplicación (actualmente Organismo Provincial de Niñez y Adolescencia) que tendría a su cargo el diseño, instrumentación, ejecución y control de políticas (art. 16 de la ley 13.298); b) la Comisión Interministerial -integrado por representantes de los distintos 
Ministerios- cuyo objetivo sería la coordinación de las políticas de optimización de los recursos del Estado Provincial y para ello debía definir acciones, priorizar agentes y sistematizar políticas públicas (art. 13 de la Ley 13298); c) el Observatorio Social, integrado por representantes de la sociedad civil e iglesias, tendría como función el monitoreo y evaluación de los programas y acciones de la promoción y protección de los derechos del niño (art. 24 de la Ley 13298 y Dec. Reglamentario 300/2005); e) el Defensor de los Derechos del Niño cuya misión sería la defensa, promoción y protección de los derechos del niño, frente a hechos, actos u omisiones de la administración Pública Provincial, Municipal o de cualquier integrante del Sistema de Promoción y Protección del Derecho del Niño (art.16.1 del Decreto 300/2005); f) los Servicios Zonales que funcionarían en cada región del Ministerio de Desarrollo, integrados por equipos interdisciplinarios que debían coordinar y supervisar el funcionamiento de los Servicios Locales (art. 18.4 del Decreto 300/05); g) los Consejos Locales debía realizar diagnósticos de la situación de la infancia y de la oferta de servicios y prestaciones así como los obstáculos para acceder a los mismos a nivel territorial (art. 15 del Decreto 300/2005); y h) los Servicios Locales cuya función principal sería la de facilitar que el niño que tenga amenazados o violados sus derechos, pueda acceder a los programas y planes disponibles en su comunidad (arts. 18, 19; 20, 21 de la Ley 13.298 y 18, 19, 20 y 21 del Decreto300/05). El sistema funcionaría a través de acciones desarrolladas por entes del sector público y del sector privado.

\section{Impacto de la CDN en la ciudad de La Plata: el caso de "la banda de las frazadas"}

A 30 años desde la vigencia de la CDN resulta indudable que prácticamente en todas las jurisdicciones (nacional, provincial y municipal) y poderes estatales (ejecutivo, legislativo y judicial) se han producido importantes cambios en la forma de concebir los derechos de los niños, niñas y adolescentes. Esta trasformación, 
consagrada en distintas normas, como se ha dicho, puede resumirse en el paso de una concepción de "menores" como objeto de tutela y protección, a la consideración de los niños, niñas y jóvenes como sujetos plenos de derecho (Beloff, 1992).

Sin embargo, en términos concretos de reconocimiento, goce y satisfacción de los derechos reconocidos a los niños, niñas y jóvenes, es posible relativizar el impacto real de la CDN en el ámbito local.

En el 2008, un grupo de niños y niñas que se encontraban en situación de calle y dormían en la glorieta de la Plaza San Martín de la ciudad de La Plata -que habían identificados por medios de comunicación como "la banda de la frazda"- fueron salvajemente lastimados por un grupo de policías y adultos que buscaban desalojarlos. Esta situación puso en evidencia que el Estado criminalizaba a estos niños por hechos que tenían su origen en la omisión de implementar políticas públicas de derechos humamos en los términos de la CDN (Menestrina, 2018).

En ese contexto, un grupo madres, organizaciones sociales e instituciones académicas presentaron una acción de amparo contra la Provincia de Buenos Aires y la Municipalidad de La Plata solicitando la efectiva puesta en marcha de la ley 13.298 que había creado el SPPDN.

La causa "Asociación Miguel Bru y otros c/ Provincia de Buenos Aires y otros s/ Amparo”, que tramitó en el Juzgado de Primera Instancia en lo Contencioso Administrativo nro. 1 de La Plata se erigió como una herramienta de diagnóstico acerca del estado de implementación de la ley 13.298, pues le ha permitido a las autoridades públicas contar con información actualizada acerca de la problemática de la niñez y familia -inexistente al momento de la interposición de la demanda-, pues contiene datos, informes y estadísticas entre otros elementos que se han ido colectando, de la mano de las pruebas realizadas así como de los amicus curiae presentados, que evidenciaron cuáles eran los obstáculos en el diseño, instrumentación, ejecución y control de políticas dirigidas a la niñez 
Desde una perspectiva general acerca del funcionamiento de las áreas de niñez, se puso de manifiesto que si bien se habían implementado una serie de programas destinados a dar cumplimiento al mandato legal, los mismos no resultaban suficientes para cubrir de modo efectivo las demandas que afectaban al colectivo de niños, niñas y adolescentes en situación de calle en la ciudad de La Plata. Se explicitó como una constante la escasa cantidad de recursos, la precariedad de las intervenciones, la falta de protocolos de actuación y la construcción diaria de estrategias basadas en las convicciones propias de los operadores, evidenciando que las diferentes intervenciones estatales no estaban sustentadas en políticas públicas serias que permitieran un trabajo coherente y sostenido en el tiempo.

Tras cuatro años, el 22 de mayo del año 2012 se dictó la sentencia que hizo lugar a la acción de amparo, condenando a la Provincia de Buenos Aires y a la Municipalidad de La Plata a que, dentro del plazo de seis meses procedieran a realizar todas las acciones necesarias para la implementación efectiva del SPPDN en la ciudad de La Plata. La sentencia fue apelada en el año 2012 y recién 8 años después, en 2020, la Suprema Corte de Justicia de la Provincia de Buenos Aires dicta una sentencia definitiva.

\section{Conclusión}

La plena y efectiva implementación de la CDN exige, desde 1990, profundas transformaciones no sólo en la legislación nacional y provincial, sino -y seguramente estas sean las más importantes- reformas en las concepciones y prácticas de los actores e instituciones relacionadas con la niñez y juventud y cambios socio-culturales de la relación del Estado, la familia y la comunidad con los niños, niñas y adolescentes. Este compromiso, que es de todo el Estado argentino, constituye aún hoy una deuda pendiente.

En términos generales la República Argentina, y la Provincia de Buenos Aires han llevado adelante una adecuación 
meramente eufemística de la legislación interna en relación al estándar de la CDN. A este tipo de procesos se los ha denominado de adecuación formal o eufemística porque se modifica la legislación pero no cambian las concepciones y prácticas (Beloff, 2004). Estos procesos, así llevados a cabo, son llamados "fraude de etiquetas" porque en sólo se trata de un cambio de nombres vacío de contenido.

En la ciudad La Plata, a través de los datos, informes y pruebas relevados en la causa "Asociación Miguel Bru” se puso de manifiesto, la inexistencia de diagnósticos precisos acerca de las problemáticas de niñez en la ciudad, las estimaciones presupuestarias, los equipos de trabajo necesarios y las evaluaciones de propuestas, requisitos indispensables no sólo para la formulación de políticas públicas, sino también para monitorear su incidencia y, eventualmente, efectuar correcciones. Se advirtió incluso falencias en el relevamiento de datos oficiales actualizados -mucho menos de acceso público- específicamente generados para los niños, niñas y adolescentes.

Dicha causa judicial reflejó -con absoluta vigencia- una tendencia a la construcción de políticas y programas centrada en la esfera retórica, que se renueva con el cambio de cada gestión, y que luego no tienen un impacto directo ni son capaces de transformar la vida de los niños cuyos derechos se encuentran vulnerados o amenazados. Todo lo dicho evidencia -aún en la actualidad- una imposibilidad absoluta de elaborar políticas con criterios de integralidad, universalidad, e interdependencia entre los diversos organismos.

Así, es posible afirmar que en que en el ámbito de la Ciudad de La Plata no existen políticas eficaces de protección y promoción de derechos para la niñez y la adolescencia,

Desde una perspectiva crítica, al cumplirse 30 años de la incorporación de la CDN al ordenamiento jurídico nacional, no caben dudas, que las reformas introducidas en el ámbito local -tanto en las leyes como en las instituciones- en materia de niñez y juventud operaron solamente como una adaptación 
formal del derecho interno a la CDN, pues no obstante la derogación formal del sistema tutelar y su reemplazo por el de la protección integral, la realidad demuestra que aquél subsiste en legitimadas y continuas prácticas administrativas y judiciales.

\section{Bibliografía}

BELAUNZARÁN, Lucia et al (2015) Niñez y Derechos bumanos. Herramientas para un abordaje integral. Editorial UNLP, La Plata.

BELOFF, Mary, No hay menores de la calle, en "No Hay Derecho", Buenos Aires, $n^{\circ}$ 6, junio de 1992.

BELOFF, Mary (2004). Los derechos del niño en el sistema interamericano, Editores del Puerto.

GUEMUREMAN, Silvia y DAROQUI, Alcira (2001). La niñez ajusticiada, Editores Del Puerto, Buenos Aires.

MENESTRINA, M., BORREGO, C., BELAUNZARAN, L., PAGANO, S., FLAHERTY, M., \& ZAPICO, L. (2018). Niñez y Derechos Humanos: entre el desamparo y la justicia. Revista Derechos En Acción, Vol. 9 Núm. 9 (2018): primavera 2018. ISSN 25251678. Disponible en https://doi.org/10.24215/25251678e241

NACIONES UNIDAS, COMITÉ DE LOS DERECHOS DEL NIÑO, Observaciones Finales: Argentina, CRC/C/15.Add.187, del 9-X2002. 